\title{
Facebook usage by students in higher education
}

\author{
N.F. Wesseling* \\ * Amsterdam University of Applied Sciences (the Netherlands) \\ n.f.wesseling-weijers@hva.nl
}

\begin{abstract}
In this paper I measure first year student Facebook usage as part of a broader $\mathrm{PhD}$ study into the influence of social media usage on the success of students in higher education. A total of 906 students were asked to complete 3 surveys on Facebook usage with their peers, for two consecutive years (2011-2012 and 2012-2013). The different purposes for Facebook usage, in addition to whether or not students used (self-created) Facebook-groups, were measured and the relationship between the use of pages compared to the purpose of Facebook usage. This resulted in significant correlations between the purpose of Facebook usage and the use of different pages, as well as correlations between the purpose and use of different pages. This study hereby explores the variation in student Facebook usage and provides valuable insight into the potential value of Facebook for students in an educational setting, without the interference of teachers. It is also the next logical step in revising existing integration and engagement theories that predict student success in higher education in contemporary society.
\end{abstract}

Keywords: Facebook, student success, higher education, social network site, integration theory, engagement.

\section{Introduction}

This study measures Facebook usage between first year students in the Department of Media, Communication and Information, at the Amsterdam University of Applied Sciences for two consecutive years (2011-2012 and 2012-2013 later referred to as 2011 and 2012), and forms part of my $\mathrm{PhD}$ research into the potential correlation between social media usage and the success of first year students in higher education.

Research into student success in the Netherlands is greatly influenced by Tinto's integration theory $(1975,1993)$, in which he states that the more a student is integrated, the less chance there is of attrition. However, this integration theory dates back to the late 1970's and is based on the American situation, and thus requires adjusting to reflect the contemporary Dutch situation. Whilst Tinto ascribes a positive influence to campuses in comparison to commuting colleges for example, such residential institutions rarely exist in the Netherlands. He states that commuting colleges don't benefit from a significant on-campus community and argues that these students are likely to spend less time interacting with fellow students (Tinto, 1993), compared to residential students.

However, in contrast to the American '80/'90's situation, modern Dutch students enjoy new ways of interacting with their peers, without necessarily being physically present at the institute. Indeed, the way in which most of us interact has changed significantly in the last 7 years, with Ping, WhatsApp and social media platforms, such as Facebook (FB) and Twitter, all emerging. And, although FB isn't the only social network site (SNS); it's by far the most popular amongst students (Hargittai, 2008; Junco, 2012c; Special \& Li-Barber, 2012; Wesseling, 2012a).

\section{Facebook and Education}

Research into the influence of FB on education has increased in line with its growth. Some studies into FB usage focused on the potential difference in students' average grade point (GPA) between FB users and non-users (Kirschner \& Karpinski, 2010; 
Kolek \& Saunders, 2008). Others centred on the difference between time spent on FB per day or week, and/or the number of applications and groups used (H.E.R.I., 2007; Heiberger, 2008; Junco, 2012d; Kirschner \& Karpinski, 2010; Wohn \& LaRose, 2014), or frequency of use of different activities (Junco, 2012c, 2012d). A few studies also measured the influence of FB usage in class or during study (multitasking) (Junco, 2012a, 2012b; Rosen, Carrier \& Cheever, 2013). And almost every study compared FB usage with the amount of time and effort a student spent in educational activities (H.E.R.I., 2007; Heiberger, 2008; Junco, 2012c, 2012d; Kirschner \& Karpinski, 2010). However, these studies were inconsistent in their findings. 'The Higher Education Research Institute (2007) and Heiberger's (2008) study both found a positive correlation between time spent on FB and student engagement. Kirschner (2010), Junco (Junco, 2012c, 2012d) and Wohn \& LaRose (2014) on the other hand, found a negative correlation to the hours spent on FB when compared to overall GPA. In the latter this relationship was negligible. Junco also found, a) a negative correlation between the frequency of posting updates on FB and GPA and, b) the higher the frequency of chat function usage, the less time a student spent studying. However, he found a positive correlation between checking friends on FB and GPA. In two additional studies, Junco (2012a, 2012b) found that, when used as a multitasking tool, FB had a negative influence on GPA' (Wesseling, in review).

A potential explanation for the contradictory results in the above-mentioned studies, is that they each measured FB usage in their own individual way. They did, however, all focus on the quantitative aspects of FB usage. As proposed in a previous paper (Wesseling, 2012b), I on the other hand measure FB usage not by quantity or amount of time spent, but rather by quality of usage (determined via the categorisation of the purpose of FB usage). Furthermore, this study focuses exclusively on contact between students, without teacher contact, initiation, coordination or participation, even as a silent member of a FB group or community. This is in direct contrast to other studies on FB usage and its engaging factor, where teachers and students do have FB contact in one form or another (Bosch, 2009; Çoklar, 2013; De Villiers, 2013; Ivala, 2012; Rambe, 2011, 2014) - studies that do reveal an engaging factor of FB within education.

\section{Methods}

Although I focus on the quality of FB usage, this doesn't imply that my study employs a qualitative method. On the contrary, the data is gathered from selfreported FB usage by students. All first-year students in the Department of Media, Communication and Information at Amsterdam University of Applied Science were sent digital surveys with fixed answer categories for two consecutive years (2011 and 2012). In both years 904 students were enlisted at the beginning of the year. Each student was supplied with three Google doc surveys throughout the college year (from September to July). The data from these surveys was subsequently downloaded into an SPSS file using Microsoft Excel. After screening for anomalies ${ }^{1}$, it was then analysed using PASW (formally SPSS) Statistics 22.0. Although the surveys were part of a career-counselling program, not all students participated.

\footnotetext{
1 Some students filled out the survey more than once. In those cases the last entry was used independent of the answers given.
} 
This led to a diminished participation during the course of the year ${ }^{2}$. All three surveys remained unchanged in the second year, except for the distribution timing of the third survey. They were sent via email to student addresses provided by the Institution.

The first survey (conducted in January 2012 and 2013) measured general student FB usage. The second survey investigated the way in which students communicate with each other and whether or not they use FB for communication with other students and if so, whether they use individual pages: 1) project group (6-9 students per group), 2) class page (+/- 30 students per class) and 3 ) year page (all first year students, max. 904). The purpose of FB usage was measured using four different categories: 1) information sharing (receiving/providing information and generating ideas), 2) sharing for educational purposes (for learning, problem solving and sharing of work), 3) social purposes (retrieving personal information about others or themselves, to chat, make appointments and generally keep in touch), 4) leisure (gaming and relaxation). The third survey, conducted in May/June (2011 cohort) and in April/May (2012 cohort), additionally measured the use of different FB pages.

\section{Results and Discussion}

The students identified Ping and WhatsApp as the most popular services. Indeed, in 2011 and 2012, some $51.9 \%$ and $88.4 \%$ of respondents respectively specified these as their preferred method for contacting other students. However, the surveys also revealed that students use FB for such contact. For the 2011 cohort, some 95.3\% of respondents had contact with other students via FB, whilst in 2012 the percentage increased still further to $98.5 \%$. As the year progressed the percentages of various FB pages used by students also increased. Over the two consecutive years, project page use increased from $37.2 \%$ to $89 \%$ (2011), and $58.1 \%$ to $88.4 \%$ (2012). The class page appeared somewhat less popular in 2011; increasing from $24.5 \%$ to $57.2 \%$. However, as it was mandatory to join the class page in the 2012 career-counselling module, the two years were not compared. Finally, the first year page witnessed the largest rise in 2011; from $8.3 \%$ to $71.0 \%$, and in 2012 ; from $16.8 \%$ to $74.6 \%$. Clearly, students use FB for contact with each other, without either encouragement from, or request to do so by teachers.

In 2011, some $76.9 \%$ of students used SNS for social purposes, and in 2012, some $68 \%$. FB usage for the purpose of exchanging information was $72.6 \%$ and $91.7 \%$ for both years respectively. In 2011, some $57.6 \%$ of students used FB for educational purposes, whilst in 2012 this grew to $66.6 \%$. Leisure recorded the lowest score: just $24.8 \%$ and $8.5 \%$ respectively.

The purpose of FB usage was tested for any correlation to the use of different FB pages, using Spearman's rho (one-tailed), displayed in table $1^{3}$. As shown in the third

\footnotetext{
${ }^{2}$ When taking into account the number of dropouts (voluntarily or mandatory due to insufficient study results) the percentages of participants in 2011 were: 88.94\% in September 2011 (804 out of 904 students), 76.50\% in January 2012 (599 out of 783 students) and 55.11\% in June 2012 (415 out of 744 students). In 2012 the percentages were: 85.73\% in September 2012 (775 out of 904 students), 59.34\% in January (432 out of 728 students) and 39.88\% in April (276 out of the 692 students).

${ }^{3}$ Due to the limited number of pages available, all output related to this correlation has been compiled in one table.
} 
column of table 1, there's both a demonstrable positive and negative correlation between the purpose of FB usage and the use of different FB pages. With a correlation coefficient of 0.300 , the most significant $(\alpha=0.01$ ) positive relationship in 2011was found between FB usage for educational purposes and the membership of a FB project group page.

Table 1. Correlation purpose of Facebook usage and contact by Facebook and the use of pages survey 2 in (January), 2011 and 2012.

\begin{tabular}{|c|c|c|c|c|c|c|}
\hline $\begin{array}{l}\text { Purpose of } \\
\text { Facebook } \\
\text { usage }\end{array}$ & $\begin{array}{l}\text { Facebook } \\
\text { contact and } \\
\text { pages }\end{array}$ & $\begin{array}{l}2011 \\
\text { Spearman's } \\
\text { rho }\end{array}$ & $\begin{array}{l}2012 \\
\text { Spearman's } \\
\text { rho }\end{array}$ & $\begin{array}{l}\text { Correlation within purpose, } \\
\text { between contact \& page use \& } \\
\text { within page use }\end{array}$ & $\begin{array}{l}2011 \\
\text { Spearman's } \\
\text { rho }\end{array}$ & $\begin{array}{l}2012 \\
\text { Spearman's } \\
\text { rho }\end{array}$ \\
\hline Information & Contact & $0.179 * *$ & 0.009 & Information /Education & $0.501^{* *}$ & $0.150 * *$ \\
\hline Information & Project page & $0.227 * *$ & -0.010 & Information/Social & -0.024 & $0.280 * *$ \\
\hline Information & Class page & $0.250 * *$ & $0.144 !^{* *}$ & Information/Leisure & $-0.126 * *$ & 0.000 \\
\hline Information & Year page & $0.106 * *$ & 0.068 & Education/Social & 0.030 & $0.177 * *$ \\
\hline Education & Contact & $0.181^{* *}$ & 0.030 & Education/Leisure & -0.027 & 0.072 \\
\hline Education & Project page & $0.300 * *$ & $0.146 * *$ & Social/Leisure & $0.316^{* *}$ & $0.151^{* *}$ \\
\hline Education & Class page & $0.225^{* *}$ & $-0.015 !$ & Contact/Project & $0.192 * *$ & $0.081^{*}$ \\
\hline Education & Year page & $0.077 *$ & 0.051 & Contact/Class & $0.114 *$ & $0.200 ! * *$ \\
\hline Social & Contact & $0.177^{* *}$ & -0.017 & Contact/Year & $0.159 * *$ & 0.032 \\
\hline Social & Project page & 0.045 & $0.115^{* *}$ & Project/Class & 0.051 & $-0.182 !^{* *}$ \\
\hline Social & Class page & -0.040 & $0.137 ! * *$ & Project/Year & -0.013 & $-0.370 * *$ \\
\hline Social & Year page & $-0.090 * *$ & $0.079 *$ & Class/Year & 0.048 & -0.026 \\
\hline Leisure & Contact & 0.046 & $-0.106 *$ & & & \\
\hline Leisure & Project page & $-0.199 * *$ & 0.009 & & & \\
\hline Leisure & Class page & $-0.098 *$ & $0.077 !$ & & & \\
\hline Leisure & Year page & 0.013 & 0.037 & & & \\
\hline
\end{tabular}

Other correlations greater than $0.199(\alpha=0.01)$ in 2011 were found between: FB usage for information sharing and a) membership of a class page $(0.250, \alpha=0.01)$ and b) membership of a project page $(0.227, \alpha=0.01)$, FB for educational purposes and membership of a class page $(0.225, \alpha=0.01)$. The most negative correlation coefficient $(-0.199, \alpha=0.01)$ in 2011 was found between FB usage for leisure purposes and contact via a project page. There are also correlations between the various categories of FB usage. The most powerful correlation of all, however, was not between the purpose of FB usage and the use of a particular page, but rather between $\mathrm{FB}$ usage for education and information (0.501, $\alpha=0.01)$. Another demonstrable correlation exists between $\mathrm{FB}$ usage for leisure and social $(0.316, \alpha$ $=0.01$ ). These figures are even more compelling when taking into account the negative correlation between FB usage for leisure and FB usage for information ($0.126, \alpha=0.01)$.

Table 2 (column three) displays correlations between the purpose of FB usage, measured in the second survey (January 2012), and contact via FB and the use of pages in the third survey (June 2012). None of the correlations are greater than 0.199. The strongest of these weaker correlations exists between the use of a FB project page and information sharing $(0.172, \alpha=0.01)$. Other weak correlations exist between: project page and education- $(0.124, \alpha=0.05)$ and social use $(0.130, \alpha=0.01)$; the use of a class page and information $(0.112, \alpha=0.05)$ and education $(0.115, \alpha=0.05)$ and social 
$(0.116, \alpha=0.05)$; contact via FB and the use of a project page $(0.192, \alpha=0.01)$, class page $(0.114, \alpha=0.05)$ and year page $(0.159, \alpha=0.01)$.

Table 2. Correlation between purpose of Facebook usage and contact by Facebook and the use of pages. Purpose of Facebook usage taken from survey 2 in 2011 and 2012, contact and page use taken from survey 3 in 2011 and 2012.

\begin{tabular}{|c|c|c|c|c|c|c|}
\hline $\begin{array}{l}\text { Purpose of } \\
\text { Facebook } \\
\text { usage (survey } \\
\text { 2) }\end{array}$ & $\begin{array}{l}\text { Facebook contact } \\
\text { and pages (survey } \\
\text { 3) }\end{array}$ & $\begin{array}{c}2011 \\
\text { Spearman's rho }\end{array}$ & $\begin{array}{c}2012 \\
\text { Spearman's rho }\end{array}$ & $\begin{array}{l}\text { Correlation within } \\
\text { contact and page } \\
\text { use survey } 3\end{array}$ & $\begin{array}{c}2011 \\
\text { Spearman's rho }\end{array}$ & $\begin{array}{c}2012 \\
\text { Spearman's rho }\end{array}$ \\
\hline Information & Contact & 0.061 & 0.032 & Contact/Project & $0.192 * *$ & 0.071 \\
\hline Information & Project page & $0.172 * *$ & -0.006 & Contact/Class & $0.114 *$ & 0.142 !** \\
\hline Information & Class page & $0.112 *$ & $-0.022 !$ & Contact/Year & $0.159 * *$ & $0.100 *$ \\
\hline Information & Year page & 0.039 & $0.141^{*}$ & Project/Class & 0.051 & -0.027 \\
\hline Education & Contact & 0.037 & 0.038 & Project/Year & -0.013 & 0.049 \\
\hline Education & Project page & $0.124 *$ & -0.002 & Class/Year & 0.048 & $0.145^{* *}$ \\
\hline Education & Class page & $0.115^{*}$ & $-0.114 !$ & & & \\
\hline Education & Year page & -0.011 & 0.032 & & & \\
\hline Social & Contact & $0.125^{*}$ & 0.102 & & & \\
\hline Social & Project page & $0.130 * *$ & 0.108 & & & \\
\hline Social & Class page & $0.116^{*}$ & $-0.028 !$ & & & \\
\hline Social & Year page & $0.109 *$ & 0.090 & & & \\
\hline Leisure & Contact & 0.068 & 0.037 & & & \\
\hline Leisure & Project page & -0.077 & $0.120^{*}$ & & & \\
\hline Leisure & Class page & -0.045 & $0.070 !$ & & & \\
\hline Leisure & Year page & 0.082 & 0.057 & & & \\
\hline
\end{tabular}

Although the correlation between FB usage for educational purposes and the membership of a Facebook project group page is weaker in 2012 (see table 1), it's also the strongest correlation found that year; $0.146(\alpha=0.01)$. Unlike 2011, the strength of this and all other significant correlations is less than 0.199. However, this is not the case for the correlation between the use of different pages and purposes. The greatest correlation for the use of different pages is found between social and information $(0.280, \alpha=0.01)$. Remaining correlations of note are less than 0.199 (social/education; 0.177, $\alpha=0.01, \quad$ social purposes/leisure; $0.151, \quad \alpha=0.01$, education/information; 0.150, $\alpha=0.01$ ). Although negative, the second strongest correlation thus far, is between the use of a project- and a year page $(-0.370, \alpha=0.01)$. The use of FB for contact has a positive correlation with the class page $(0.200$, $\alpha=0.01$ ). The weak, yet negative correlation between the use of a project- and class page $(-0.182, \alpha=0.01)$ in 2012 is unexpected, especially bearing in mind the mandatory membership of a class page as part of the career-counselling program that year. The correlations between purpose of FB usage (measured in the second survey) and contact via FB and the use of pages (in the third survey) are also displayed in table 2 (column seven). Again, in 2012, none of these correlations are greater than 0.199 . 


\section{Conclusions}

Certain correlations were expected, such as FB usage for educational purposes and the use of a project page; the positive correlation between education and information and the use of a class and a year page; contact via FB and its use for education and information; the use of a project and a class page with education and information. It's also not surprising that social purposes positively correlate with contact and use of different pages. When accompanied by the negative correlation between, 1) leisure and a), the use of a project and, b) of a class page in 2011 and, 2) between leisure and FB contact in 2012, it appears that those using FB for educational purposes, do so via their FB page and project page; those using FB for leisure purposes on the other hand, make less use of a project or class page. The negative correlation in the second survey of 2012, between the use of a project page and a year page, and the slightly negative correlation with class page, supports the notion that those using FB in small groups (project) don't use year or class pages. These correlations do, however, provide an even greater incentive for measuring SNS activities, particularly if one wishes to accurately predict student success using (elements of) the integration and engagement theory. Furthermore, those less positive correlations found in 2012, when membership of a class page was mandatory, and the negative correlations between the use of a class page and contact between students, membership of a project page and FB usage for social purposes, demonstrate that Facebook isn't necessarily a positive influence on education. One might even go as far as to suggest that teachers shouldn't interfere, by keeping 'their' tools separate, or by using another platform with the same capabilities, which is more informal and less distracting.

\section{References}

Bosch, T. E. (2009). Using online social networking for teaching and learning: Facebook use at the University of Cape Town. Communicatio: South African Journal for Communication Theory and Research, 35(2), 185-200.

Çoklar, A., N. (2013). Evaluations of students in Facebook as an educational environment. Turkish Online Journal of Qualitative Inquiry, 3(2), 42-53.

De Villiers, M. R., Pretorius, M.C., Nagle, T., Sammon, D. (2013). Evaluation of a Collaborative Learning Environment on a Facebook Forum. The Electroninc Journal Information Systems evaluation, 16(1), 56-70.

H.E.R.I. (2007). College freshman and online social networking sites: Higher Education Research Institute.

Hargittai, E. (2008). Whose Space? Differences Among Users and Non-Users of Social Network Sites. Journal of Computer-Mediated Communication, 13(1), 276-297. doi: 10.1111/j.1083-6101.2007.00396.x

Heiberger, G. H., R. (2008). Have you Facebooked Astin lately? Using technology to increase student involvement. In R. T. Junco, D.M. (Ed.), Using emerging technologies to enhance student engagement. New Directions for Student Services (Vol. 124, pp. 19-35). San Francisco, CA: Jossey-Bass.

Ivala, E., Gachago, D. (2012). Social media for enhancing student engagement: the use of Facebook and blogs at the University of Technolojgy South African Journal of Higher education, 26(1), 152-167. 
Junco, R. (2012a). In-class multitasking and academoc performance. Computers in Human Behavior, 28, 2236-2243. doi: 10.1016/j.chb.2012.06.031

Junco, R. (2012b). No A 4 U: The relationship between multitasking and academic performance. Computers \& Education, 59, 505-514. doi: 10.1016/j.compedu.2011.12.023

Junco, R. (2012c). The relationship between frequency of Facebook use, participation activities, and student engagement. Computers \& Education, 25, 162-171. doi: 10.1016/j.compedu.2011.08.004

Junco, R. (2012d). Too much face and not enough books: The relationship between multiple indices of Facebook use and academic performance. Computers in Human Behavior(28), 187-198. doi: 10.1016/j.chb.2011.08.026

Kirschner, P. A., Karpinski, A.C. (2010). Facebook and academic performance. Computers in Human Behavior, 26(1237-1245).

Kolek, E. A., Saunders, D. (2008). Online disclosure: An empirical examination of undergraduate Facebook profiles. NASPA Journal, 45(1), 1-25.

Rambe, P., Ng'ambi, D. (2011). Towards an information sharing pedagogy: A case of using Facebook in a large first class. Informing Science: the International Journal of an Emerging Transdiscipline, 14, 61-89.

Rambe, P., Ng'ambi, D. (2014). Learning with and from Facebook: Uncovering power asymmetries in educational interactions. Australian Journal of Education Technology, 30(3), 312-325.

Rosen, L. D., Carrier, L.M., Cheever, N.A. (2013). Facebook and texting made me do it: Media-induced task-switching while studying. Computers in Human Behavior, 29, 948-958. doi: 10.1016./j.chb2012.12.001

Special, W. P., Li-Barber, T.K. (2012). Self-disclosure and student satisfaction with Facebook. Computers in Human Behavior(28), 624-630. doi: 10.1016/j.chb.2011.11.008

Tinto, V. (1975). Dropout from higher education. Review of Educational Research, 45(1), 89-125.

Tinto, V. (1993). Leaving College: Rethinking the Causes and Cures of Student Attrition (Rev.ed) (2 ed.). Chicago: University of Chicago Press.

Wesseling, N. F. (2012a). Differences in computer usage and background variables of first year students in higher education. Paper presented at the 6th annual International Technology, Education and Development Conference, Valencia, 5-7 March, Spain.

Wesseling, N. F. (2012b). How students use Facebook. Paper presented at the WEI International European Academic Conferennce Proceedings, Zagreb 14-17 September, Croatia.

Wesseling, N. F. (in review). New ways of engagement in higher education. The International Journal of Technology, Knowledge and Society.

Wohn, D. Y., LaRose, R. (2014). Effects of loneliness and differantial usage of Facebook on college adjustment of first-year students. Computers \& Education, 76, 158-167. doi: 10.1016/j.compedu.2014.03.018 